\title{
Efeito da substituição da farinha de trigo no desenvolvimento de biscoitos sem glúten
}

\author{
Effect of wheat flour substitution on the development of gluten-free cookies
}

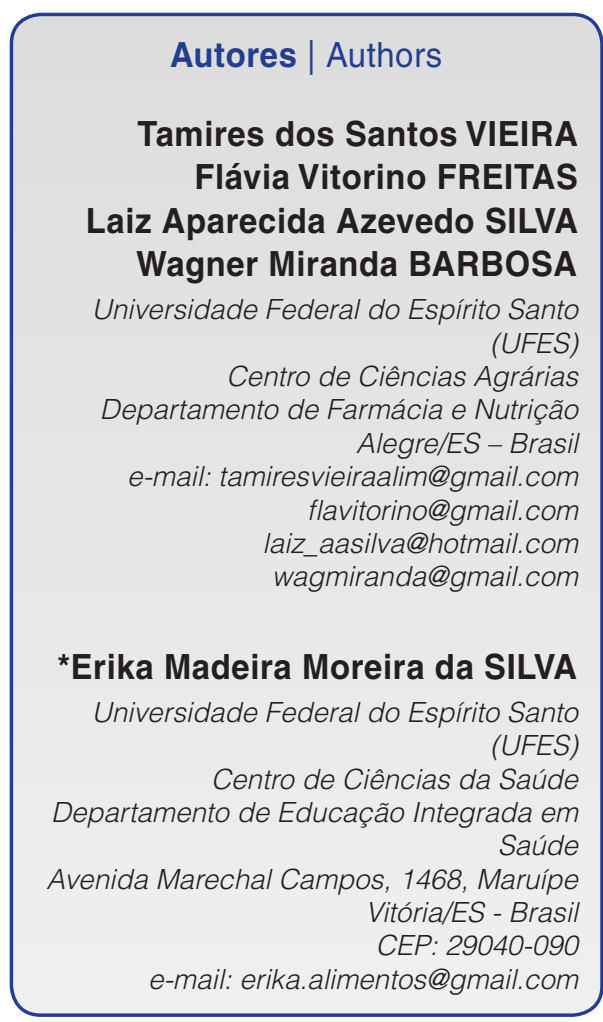

*Autor Correspondente / Corresponding Author

Recebido: Abr. 15, 2015

Aprovado: Dez. 07, 2015

\section{Resumo}

O glúten pode determinar a qualidade da farinha de trigo, conferindo às massas características como elasticidade e capacidade de absorver água, o que torna a elaboração de produtos de panificação isentos de glúten um desafio. Desse modo, o presente estudo buscou avaliar as características físico-químicas e sensoriais de biscoitos elaborados com ingredientes sucedâneos ao trigo, como fécula de mandioca, farinha de soja, de quinoa e de amaranto. Para a caracterização física foram determinados: peso, diâmetro, espessura, fator de expansão e volume específico. Quanto à composição química foram determinados: umidade, cinzas, proteínas, lipídios, fibras alimentares, carboidratos totais, energia, além de $\mathrm{pH}$ e acidez. A aceitabilidade foi determinada por meio de uma escala hedônica de nove pontos. As formulações contendo farinhas sucedâneas ao trigo apresentaram bom rendimento, maior teor de cinzas, de proteínas, de lipídios e de fibras alimentares. Também, essas apresentaram percentuais de aceitabilidade superiores a 70\%, exceto para a avaliação do sabor da amostra com maior teor de soja (40 g/100g). Conclui-se que as formulações contendo farinhas sucedâneas ao trigo podem ser consideradas promissoras, disponibilizando alternativas alimentares àqueles que almejam produtos com valor nutricional superior e posicionamento único no mercado, visto que os produtos disponíveis muitas vezes possuem baixo valor nutritivo ao serem elaborados com farinhas amiláceas.

Palavras-chave: Composição química; Panificação; Fibra alimentar; Análise sensorial.

\section{Summary}

Gluten can determine the quality of wheat flour, providing elasticity and the water holding characteristics of the dough, which makes the preparation of gluten-free bakery products a challenge. Thus the aim of this study was to evaluate the physicochemical and sensory characteristics of cookies made with wheat flour substitutes such as cassava starch, soy, quinoa and amaranth flours. The physical characterization was determined according to the weight, diameter, thickness, expansion factor and specific volume. The chemical composition was determined according to the moisture, ash, protein, fat, dietary fibre and total carbohydrate contents, and also the energy, $\mathrm{pH}$ and acidity. Acceptability was determined using a nine-point hedonic scale. The formulations containing the wheat flour substitutes showed good yields, and higher ash, protein, lipid and dietary fibre contents. They also showed percentages of acceptability above $70 \%$, except for the flavour of the sample with the highest soy content $(40 \mathrm{~g} / 100 \mathrm{~g})$. It was concluded that the formulations containing wheat flour substitutes could be considered promising alternatives for food products with superior nutritional value and a unique market opportunity, since the products available frequently have a low nutritional value due to the fact that they are elaborated with starchy flours.

Key words: Chemical composition; Bakery; Dietary fibre; Sensory analysis. 


\section{Introdução}

A farinha de trigo é largamente utilizada para a elaboração de produtos panificados devido à sua propriedade de gerar uma rede viscoelástica, insolúvel em água, a qual permite que todos os ingredientes sejam agregados para formar as massas alimentícias (ARAÚJO et al., 2010). Essa propriedade é atribuída às proteínas gliadina e glutelina, que compõem o glúten (WIESER, 2007), as quais conferem capacidade de absorção de água, coesividade, viscosidade e elasticidade às massas.

$\mathrm{Na}$ literatura é possível encontrar diversos trabalhos que estudaram a substituição parcial ou total do trigo em produtos de panificação (MARTINEZ et al., 2014; LEMOS et al., 2012; RAMOS et al., 2012; LACERDA et al., 2009; CÉSAR et al., 2006), seja para melhoria da qualidade nutricional, seja para atender a um público específico de portadores de doenças nutricionais, como os celíacos, e a um público que cada vez mais busca produtos com atrativos mais saudáveis, como a presença de fibras e compostos bioativos.

No entanto, a substituição total da farinha de trigo representa uma grande dificuldade para obtenção de produtos panificados, sendo necessária a introdução e combinação de diversos ingredientes, assim como mudanças nas técnicas tradicionais de preparo (CAPRILES; ARÊAS, 2011) com objetivo de processar produtos sensorial e tecnologicamente aceitáveis.

Biscoitos são produtos obtidos pelo forneamento e cozimento conveniente de massa preparada com farinhas, amidos, féculas fermentadas ou não e outras substâncias alimentícias (ANVISA, 1978). Segundo Mareti et al. (2010), os biscoitos possuem a capacidade de incorporar diferentes formulações e compostos bioativos sem perder suas características tecnológicas. Sendo assim, pela introdução de farinhas sucedâneas ao trigo pode-se agregar qualidade, seja pela introdução de nutrientes, fibras e outros compostos, seja pela melhoria tecnológica, sem causar prejuízos físicos e sensoriais significativos ao produto final (GANORKAR; JAIN, 2014).

A farinha de soja (Glycine max) pode ser empregada em vários produtos, seja na substituição total ou parcial do trigo, seja compondo uma mistura de farinhas (KIRINUS et al., 2010). Além de melhorar a qualidade nutricional das massas, ela favorece o cozimento e a textura do produto (SCHMIELE et al., 2013).

A adição da fécula de mandioca (Manihot esculenta Crantz) às preparações em substituição parcial ou total do trigo apresenta boa aceitação (VIEIRA et al., 2010) e contribui para a crocância e a coloração clara nos produtos elaborados. Pode também ser adicionada em misturas com farinhas isentas de glúten.
Ao serem adicionados a produtos gluten free, a quinoa (Chenopodium quinoa Willd) e o amaranto (Amaranthus mantegazzianus) podem contribuir para aumentar o valor nutritivo das formulações (CAPRILES; ARÊAS, 2011). Giovanella et al. (2013), ao elaborarem biscoitos sem glúten com $31 \mathrm{~g} / 100 \mathrm{~g}$ de farinha de quinoa e $21 \mathrm{~g} / 100 \mathrm{~g}$ de fécula de batata, observaram maior valor de proteínas $(7,4 \mathrm{~g} / 100 \mathrm{~g})$ e de cinzas $(1,9 \mathrm{~g} / 100 \mathrm{~g})$ em relação às demais formulações, assim como maior aceitação na avaliação sensorial. Por outro lado, Capriles e Arêas (2012), ao avaliarem as características tecnológicas e sensoriais de snacks elaborados com o grão e a farinha desengordurada de amaranto, variando de $50 \mathrm{~g} / 100 \mathrm{~g}$ a $100 \mathrm{~g} / 100 \mathrm{~g}$, verificaram que, com o aumento na concentração de amaranto, os parâmetros de cor e textura foram prejudicados, sendo piores quando se utilizou o grão integral. Os resultados desses autores demonstram que é preciso realizar testes com diferentes combinações de farinhas a fim de se obter melhores resultados e de se minimizar o prejuízo aos produtos elaborados.

Nesse contexto, o presente trabalho objetivou desenvolver biscoitos tipo cookies sem glúten, com a combinação de farinhas sucedâneas ao trigo: fécula de mandioca, farinha de soja, de quinoa e de amaranto, bem como avaliar as características físico-químicas e sensoriais dos biscoitos elaborados.

\section{Material e métodos}

\subsection{Formulação dos biscoitos}

Os ingredientes utilizados para a elaboração dos biscoitos foram adquiridos no comércio local (Alegre/ ES-Brasil), assim como as matérias-primas sucedâneas ao trigo: quinoa e amaranto em flocos, farinha de soja integral e fécula de mandioca. A quinoa e o amaranto foram triturados em liquidificador doméstico para obtenção da farinha.

Foram conduzidos testes preliminares objetivando adequar a proporção das farinhas sucedâneas ao trigo. Para tal foram consultados alguns estudos (VIEIRA et al., 2010; MARCILIO et al., 2005), chegando-se a duas formulações F2 (30 g/100g amaranto, $10 \mathrm{~g} / 100 \mathrm{~g}$ quinoa, $40 \mathrm{~g} / 100 \mathrm{~g}$ soja, $20 \mathrm{~g} / 100 \mathrm{~g}$ fécula de mandioca) e F3 (35 g/100g amaranto, $10 \mathrm{~g} / 100 \mathrm{~g}$ quinoa, $30 \mathrm{~g} / 100 \mathrm{~g}$ soja, $25 \mathrm{~g} / 100 \mathrm{~g}$ fécula de mandioca) alternativas ao controle (F1: $100 \mathrm{~g} / 100 \mathrm{~g}$ de farinha de trigo). Na Tabela 1 estão descritas as proporções de ingredientes.

\subsection{Caracterização física}

Dez biscoitos de uma mesma fornada foram analisados de acordo com os procedimentos descritos no método 10-50D da American Association of Cereal Chemists - AACC (AACC, 1995). Para as dimensões foram 
Efeito da substituição da farinha de trigo no desenvolvimento de biscoitos sem glúten

VIEIRA, T. S. et al.

Tabela 1. Ingredientes utilizados na formulação dos biscoitos.

\begin{tabular}{lccc}
\multicolumn{1}{c}{ Ingredientes } & F1 & F2 & F3 \\
\hline Farinha de trigo $(\mathrm{g})$ & 155,10 & - & - \\
Farinha de amaranto $(\mathrm{g})$ & - & 46,53 & 54,28 \\
Farinha de quinoa $(\mathrm{g})$ & - & 15,51 & 15,51 \\
Farinha de soja $(\mathrm{g})$ & - & 62,02 & 46,53 \\
Fécula de mandioca $(\mathrm{g})$ & - & 31,02 & 38,77 \\
Margarina (g) & 90,0 & 90,00 & 90,00 \\
Açúcar refinado $(\mathrm{g})$ & 70,0 & 70,00 & 70,00 \\
Essência de Baunilha $(\mathrm{ml})$ & 2,5 & 2,5 & 2,5 \\
\hline
\end{tabular}

medidas a espessura e o diâmetro. Para expressar as medidas de peso, diâmetro e espessura foi calculada a diferença antes e após o forneamento. O cálculo do fator de expansão foi realizado pela razão entre o diâmetro e a espessura dos biscoitos. O volume específico foi determinado pela razão entre o volume aparente e o peso dos biscoitos, expresso em $\mathrm{mL} \mathrm{g}^{-1}$. O volume aparente foi determinado pelo método de deslocamento de sementes de painço (MORAES et al., 2010).

\subsection{Caracterização química}

A caracterização química das farinhas sucedâneas ao trigo, bem como dos biscoitos, foi feita de acordo com a metodologia proposta pela Association of Official Agricultural Chemists - AOAC (HORWITZ, 2005). Foram determinados: umidade, nitrogênio (fator 6,25), cinzas, lipídios e fibras alimentares. $\mathrm{O}$ teor de carboidratos disponíveis foi calculado por diferença: 100 - (umidade + cinzas + fibra + proteínas + lipídios). O valor energético foi determinado em kcal, por cálculo. Acidez total titulável e $\mathrm{pH}$ foram determinados de acordo com a metodologia do Instituto Adolfo Lutz (2005).

\subsection{Análise sensorial}

Para o teste afetivo foram recrutados 60 avaliadores, de forma aleatória, entre estudantes e funcionários do Centro de Ciências Agrárias da Universidade Federal do Espírito Santo (CCA-UFES). As amostras, codificadas com três dígitos, foram oferecidas aos avaliadores de forma monádica e aleatória em cabines individuais, sob iluminação branca. A escala de nove pontos foi utilizada para avaliação, em que 1 correspondeu a "desgostei muitíssimo" e 9 a "gostei muitíssimo". Foram avaliados atributos sensoriais como: sabor, cor, textura e aceitação global. Além disso, os avaliadores foram questionados se "comprariam" ou "não comprariam" os biscoitos, sendo orientados a marcar na ficha de avaliação. Quanto ao cálculo do Índice de Aceitabilidade, foi levada em consideração a frequência relativa das notas, sendo consideradas bem aceitas as amostras com percentual de aceitação superior a 70\% (MEILGAARD et al., 2007). Este estudo foi submetido ao e aprovado pelo Comitê de Ética e Pesquisa do Centro de Ciências da Saúde da Universidade Federal do Espírito Santo (CCS-UFES) (parecer $n^{\circ}$ 15.528). Todos os participantes da análise sensorial assinaram um Termo de Consentimento Livre e Esclarecido.

\subsection{Tratamento dos dados}

Os resultados do estudo foram submetidos à análise de variância (ANOVA), sendo que as médias foram comparadas utilizando-se o teste Tukey, considerando 95\% de significância. As análises foram realizadas por meio do software Statistica 10.0.

\section{Resultados e discussão}

\subsection{Caracterização química das farinhas}

$\mathrm{Na}$ Tabela 2 são mostrados os resultados da caracterização química das farinhas de trigo, de amaranto, de quinoa, de soja e da fécula de mandioca. A farinha de trigo apresentou maior proporção de umidade $(13,39 \mathrm{~g} / 100 \mathrm{~g})$. No entanto, todos os resultados da composição química encontrados no presente estudo estavam de acordo com o que preconiza a legislação, 15 g/100g-18 g/100g de umidade (ANVISA, 2005), podendo ser utilizada em produtos panificados.

A farinha de soja apresentou maior proporção de proteínas $(54,56 \mathrm{~g} / 100 \mathrm{~g})$, lipídios (22,99 g/100g), cinzas $(4,21 \mathrm{~g} / 100 \mathrm{~g})$ e fibras $(10,56 \mathrm{~g} / 100 \mathrm{~g})$, seguida das farinhas de amaranto, de quinoa e da fécula de mandioca. Por outro lado, observou-se que tanto a fécula de mandioca quanto a farinha de trigo apresentaram um teor maior de carboidratos.

Neste estudo, além da farinha de soja, as farinhas de amaranto e de quinoa apresentaram valores de cinzas superiores ao da fécula de mandioca e da farinha de trigo.

O teor de proteínas determinado no amaranto e na quinoa estava de acordo com o evidenciado por Gewehr et al. (2012) e Miranda et al. (2012). Os valores observados de $\mathrm{pH}$ foram estatisticamente diferentes entre si, o que indica diferença na composição das farinhas e pode influenciar o $\mathrm{pH}$ dos biscoitos elaborados. Por outro lado, as farinhas de soja e de quinoa apresentaram proporção maior de acidez comparadas à das demais farinhas. Fatores genéticos, climáticos e do solo podem interferir na composição nutricional dos grãos (GEWEHR et al., 2012), bem como na composição das farinhas e dos produtos elaborados.

\subsection{Caracterização física dos biscoitos}

Nas três formulações de biscoito do presente estudo procurou-se manter a mesma quantidade de açúcar e margarina nas formulações, a fim de se observar o comportamento das farinhas sucedâneas. 
Efeito da substituição da farinha de trigo no desenvolvimento de biscoitos sem glúten

VIEIRA, T. S. et al.

Durante o processamento, as três formulações elaboradas apresentaram textura propícia à moldagem, não havendo necessidade de alterar a quantidade dos demais ingredientes. Na Tabela 3 podem ser visualizados os resultados da caracterização física dos biscoitos.

Houve aumento de peso nas formulações (F2 e F3) contendo farinhas sucedâneas ao trigo, não diferindo estatisticamente entre si $(p>0,05)$. Entretanto, apenas a formulação F3 apresentou maior aumento no diâmetro, na espessura e no volume específico. Observou-se também que o fator de expansão não diferiu entre as amostras, inclusive em relação à amostra-controle (F1).

Vieira et al. (2010), ao elaborarem biscoitos doces com concentrações crescentes de fécula de mandioca, variando de $0 \mathrm{~g} / 100 \mathrm{~g}$ a $15 \mathrm{~g} / 100 \mathrm{~g}$, evidenciaram valores de diâmetro após o forneamento semelhantes entre as formulações testadas, além de melhor crocância e cor à medida que a concentração aumentava. No entanto, no presente estudo observou-se que, quando comparado com a amostra F2, o aumento no teor de fécula de mandioca em combinação como a redução do teor de farinha de soja pode ter contribuído para o aumento dos parâmetros físicos analisados na amostra F3. Desse modo, sugere-se que tal fato se deve à redução no teor de lipídios provenientes da soja, bem como ao aumento do teor de amido (dado não analisado) proveniente da fécula de mandioca.

Além disso, biscoitos geralmente apresentam aumento no diâmetro depois do forneamento, o que é atribuído ao baixo conteúdo de glúten e força da farinha de trigo mole, que forma um filme frágil ao invés de rede viscoelástica (ZOULIAS et al., 2002), o que é desejável no caso de biscoitos.

Para Moura et al. (2010), o fator de expansão é utilizado como indicador de qualidade e valores muito altos ou muito baixos em biscoitos ocasionam problemas na indústria, resultando em produtos de tamanho pequeno ou peso elevado (FERREIRA et al., 2009). De acordo com Ordorica-Falomir e Paredes-Lópes (1991), a farinha ou qualquer outro ingrediente que absorve água durante a mistura da massa pode reduzir o fator de expansão.

\subsection{Caracterização química dos biscoitos}

Os resultados da composição química dos biscoitos podem ser visualizados na Tabela 4. As formulações com farinhas sucedâneas ao trigo F2 e F3 apresentaram maior teor de umidade, cinzas, proteínas, lipídios e fibras alimentares em relação à amostra F1 (controle). Observou-se que a formulação F2 apresentou maior teor de proteínas, lipídios, fibras e valor energético, bem como menor teor de carboidratos, quando comparada com a amostra F3. Tal resultado pode ser atribuído ao fato de essa formulação apresentar maior teor de soja em sua composição, como observado na Tabela 3. Quanto ao teor de lipídeos, F2 foi estatisticamente superior a F3 ( $p<0,05)$, no entanto, numericamente, os valores pouco diferiram, podendo isso ser atribuído à mesma quantidade de margarina adicionada, mesmo que a farinha de

Tabela 2. Composição centesimal das farinhas de trigo, de amaranto, de quinoa, de soja e da fécula de mandioca.

\begin{tabular}{|c|c|c|c|c|c|}
\hline Parâmetros & Trigo & Amaranto & Quinoa & Soja & $\begin{array}{l}\text { Fécula de } \\
\text { mandioca }\end{array}$ \\
\hline Umidade $(\mathrm{g} / 100 \mathrm{~g})$ & $13,39 \pm 0,07^{a}$ & $11,03 \pm 0,42^{b c}$ & $12,02 \pm 0,15^{\mathrm{ab}}$ & $4,40 \pm 0,49^{d}$ & $11,85 \pm 1,20^{\mathrm{ac}}$ \\
\hline Cinzas (g/100g) & $0,46 \pm 0,03^{d}$ & $2,04 \pm 0,01^{c}$ & $2,29 \pm 0,03^{b}$ & $4,21 \pm 0,08^{a}$ & $0,05 \pm 0,00^{e}$ \\
\hline Proteínas (g/100g) & $14,58 \pm 0,01^{c}$ & $16,23 \pm 0,24^{b}$ & $13,31 \pm 0,60^{\mathrm{cd}}$ & $54,56 \pm 1,04^{a}$ & $1,51 \pm 0,36^{e}$ \\
\hline Lipídios (g/100g) & $1,25 \pm 0,24^{\mathrm{de}}$ & $7,17 \pm 0,12^{b}$ & $4,70 \pm 1,29^{c}$ & $22,99 \pm 1,16^{a}$ & $0,46 \pm 0,15^{e}$ \\
\hline Fibras alimentares $(\mathrm{g} / 100 \mathrm{~g})$ & $2,75 \pm 0,02^{c}$ & $9,85 \pm 0,02^{a}$ & $5,42 \pm 0,04^{b}$ & $10,56 \pm 0,02^{a}$ & $0,61 \pm 0,03^{d}$ \\
\hline Carboidratos (g/100g) & $67,57 \pm 0,24^{b}$ & $53,68 \pm 0,27^{d}$ & $62,26 \pm 1,21^{\mathrm{c}}$ & $3,28 \pm 1,29^{e}$ & $85,52 \pm 1,02^{a}$ \\
\hline Energia (Kcal) & $339,85 \pm 1,53^{d}$ & $344,17 \pm 2,18^{b}$ & $344,58 \pm 6,84^{b}$ & $438,27 \pm 2,82^{a}$ & $352,26 \pm 5,28^{c}$ \\
\hline Acidez (g/100g) & $0,07 \pm 0,00^{c d}$ & $0,11 \pm 0,03^{b c}$ & $0,28 \pm 0,06^{a}$ & $0,33 \pm 0,03^{a}$ & $0,02 \pm 0,01^{d}$ \\
\hline $\mathrm{pH}$ & $5,28 \pm 0,08^{c d}$ & $5,88 \pm 0,07^{a b c}$ & $4,96 \pm 0,12^{d}$ & $6,37 \pm 0,09^{a}$ & $5,56 \pm 0,50^{\mathrm{bcd}}$ \\
\hline
\end{tabular}

Médias com a mesma letra, na mesma linha, não diferem entre si a $5 \%$ de probabilidade pelo teste Tukey.

Tabela 3. Caracterização física dos biscoitos.

\begin{tabular}{lccc}
\multicolumn{1}{c}{ Parâmetros físicos } & F1 $^{*}$ & F2 $^{*}$ & F3 $^{*}$ \\
\hline Diferença de peso $(\mathrm{g})$ & $0,94 \pm 0,07^{\mathrm{b}}$ & $1,08 \pm 0,10^{\mathrm{a}}$ & $1,04 \pm 0,10^{\mathrm{a}}$ \\
Aumento de diâmetro $(\mathrm{cm})$ & $0,34 \pm 0,07^{\mathrm{b}}$ & $0,31 \pm 0,13^{\mathrm{b}}$ & $0,69 \pm 0,06^{\mathrm{a}}$ \\
Aumento de espessura $(\mathrm{cm})$ & $0,22 \pm 0,08^{\mathrm{b}}$ & $0,24 \pm 0,05^{\mathrm{b}}$ & $0,31 \pm 0,06^{\mathrm{a}}$ \\
Fator de expansão & $3,88 \pm 0,31^{\mathrm{a}}$ & $3,68 \pm 0,48^{\mathrm{a}}$ & $4,03 \pm 0,47^{\mathrm{a}}$ \\
Volume específico $\left(\mathrm{mL} \cdot \mathrm{g}^{-1}\right)$ & $1,35 \pm 0,21^{\mathrm{b}}$ & $1,42 \pm 0,51^{\mathrm{b}}$ & $2,19 \pm 0,39^{\mathrm{a}}$ \\
\hline
\end{tabular}

Médias com a mesma letra, na mesma linha, não diferem entre si a 5\% de probabilidade pelo teste Tukey. F1* (biscoito controle contendo farinha de trigo); F2* (biscoito contendo $30 \mathrm{~g} / 100 \mathrm{~g}$ de amaranto, $10 \mathrm{~g} / 100 \mathrm{~g}$ de quinoa, $40 \mathrm{~g} / 100 \mathrm{~g}$ de soja e $20 \mathrm{~g} / 100 \mathrm{~g}$ de fécula de mandioca); F3* (biscoito contendo $35 \mathrm{~g} / 100 \mathrm{~g}$ de amaranto, $10 \mathrm{~g} / 100 \mathrm{~g}$ de quinoa, $30 \mathrm{~g} / 100 \mathrm{~g}$ de soja e $25 \mathrm{~g} / 100 \mathrm{~g}$ de fécula de mandioca). 
Efeito da substituição da farinha de trigo no desenvolvimento de biscoitos sem glúten

VIEIRA, T. S. et al.

soja adicionada apresentasse teor de lipídios superior $(22,99 \mathrm{~g} / 100 \mathrm{~g})$ ao das demais farinhas, a quantidade adicionada não representou grandes alterações nesse parâmetro. Além disso, a formulação F2 apresentou maior teor de acidez. Por outro lado, a formulação F3 apresentou o maior $\mathrm{pH}$.

Todas as formulações estão de acordo com a recomendação da legislação para umidade em biscoitos, de até $14 \mathrm{~g} / 100 \mathrm{~g}$ (ANVISA, 1978). O maior conteúdo de umidade em biscoitos pode favorecer as reações enzimáticas de deterioração, bem como a multiplicação de micro-organismos deteriorantes e patogênicos. Além disso, afeta a qualidade sensorial do produto final, tornando a textura dos biscoitos amolecida e desagradável. A composição das farinhas utilizadas nas formulações F2 e F3 pode ter contribuído para uma maior umidade nos biscoitos, uma vez que possuíam alto teor de fibras e proteínas em relação à farinha de trigo (Tabela 3). Para Cauvain e Young (2002), a absorção de água em produtos panificados depende de dois fatores, o conteúdo de fibras e de proteínas da massa. No entanto, outros fatores, como absorção de umidade ambiente, teor de amido danificado, também pode justificar esse aumento. A acidez representa um importante parâmetro do estado de conservação de um produto (UCHOA et al., 2008). Para biscoitos, a acidez máxima permitida corresponde a 2 g/100g (ANVISA, 1978). Dessa forma, os biscoitos apresentaram acidez adequada. Em relação ao pH, quando entre 4,5 a 7 o crescimento de bolores pode ser favorecido (JAY, 2005), o que pode limitar o tempo de prateleira desse produto.

\subsection{Análise sensorial}

$\mathrm{Na}$ Tabela 5 visualizam-se os resultados para sabor, textura, cor e aceitação global das três amostras testadas.

De acordo com os resultados da análise sensorial, observou-se que a formulação-controle (F1) apresentou maiores médias de aceitação para sabor, textura e aceitação global. Entretanto, a formulação F2 também apresentou boa avaliação quanto ao atributo cor. De forma geral, a média de aceitação global foi, na escala hedônica, entre "gostei moderadamente" e "gostei ligeiramente".

Em estudo conduzido por Marcilio et al. (2005), as melhores notas foram atribuídas aos biscoitos elaborados com maior teor de lipídios. Entretanto, no presente estudo, as formulações F2 e F3 apresentaram sabor de gordura acentuado. Por outro lado, alguns avaliadores comentaram na ficha de aceitação que os biscoitos possuíam um sabor residual que não souberam identificar, o que poderia ser justificado pelo uso da farinha integral de soja. Vieira et al. (2010), ao elaborarem biscoitos doces com fécula de mandioca, observaram que a presença de $15 \mathrm{~g} / 100 \mathrm{~g}$ desse ingrediente permitiu uma coloração mais clara do produto final. Observou-se que a formulação F2 (contendo $20 \mathrm{~g} / 100 \mathrm{~g}$ de fécula de mandioca) apresentou resultado para cor semelhante à formulação controle (F1).

Tabela 4. Composição centesimal dos biscoitos.

\begin{tabular}{lrrr}
\multicolumn{1}{c}{ Parâmetros } & \multicolumn{1}{c}{ F1 $^{*}$} & F2 $^{*}$ & F3* $^{*}$ \\
Umidade (g/100g) & $1,97 \pm 0,06^{\mathrm{c}}$ & $2,38 \pm 0,00^{\mathrm{b}}$ & $3,60 \pm 0,09^{\mathrm{a}}$ \\
Cinzas (g/100g) & $0,64 \pm 0,13^{\mathrm{b}}$ & $1,60 \pm 0,03^{\mathrm{a}}$ & $1,43 \pm 0,02^{\mathrm{a}}$ \\
Proteínas (g/100g) & $10,03 \pm 0,36^{\mathrm{c}}$ & $17,15 \pm 0,17^{\mathrm{a}}$ & $14,59 \pm 0,51^{\mathrm{b}}$ \\
Lipídios (g/100g) & $24,84 \pm 0,18^{\mathrm{c}}$ & $29,93 \pm 0,68^{\mathrm{a}}$ & $28,63 \pm 0,8^{\mathrm{b}}$ \\
Fibras alimentares (g/100g) & $1,21 \pm 0,02^{\mathrm{c}}$ & $4,23 \pm 0,02^{\mathrm{a}}$ & $3,52 \pm 0,17^{\mathrm{b}}$ \\
Carboidratos (g/100g) & $61,31 \pm 0,46^{\mathrm{a}}$ & $44,71 \pm 0,59^{\mathrm{c}}$ & $48,23 \pm 1,02^{\mathrm{b}}$ \\
Energia (kcal) & $508,92 \pm 5,07^{\mathrm{a}}$ & $516,81 \pm 8,70^{\mathrm{b}}$ & $508,95 \pm 9,97^{\mathrm{a}}$ \\
Acidez (g/100g) & $0,03 \pm 0,00^{\mathrm{c}}$ & $0,07 \pm 0,01^{\mathrm{a}}$ & $0,04 \pm 0,01^{\mathrm{bc}}$ \\
pH & $5,93 \pm 0,19^{\mathrm{c}}$ & $6,76 \pm 0,34^{\mathrm{b}}$ & $7,19 \pm 0,16^{\mathrm{a}}$ \\
\hline
\end{tabular}

Médias com a mesma letra, na mesma linha, não diferem entre si a $5 \%$ de probabilidade pelo teste Tukey. F1* (biscoito controle contendo farinha de trigo); F2* (biscoito contendo $30 \mathrm{~g} / 100 \mathrm{~g}$ de amaranto, $10 \mathrm{~g} / 100 \mathrm{~g}$ de quinoa, $40 \mathrm{~g} / 100 \mathrm{~g}$ de soja e $20 \mathrm{~g} / 100 \mathrm{~g}$ de fécula de mandioca); F3* (biscoito contendo $35 \mathrm{~g} / 100 \mathrm{~g}$ de amaranto, $10 \mathrm{~g} / 100 \mathrm{~g}$ de quinoa, $30 \mathrm{~g} / 100 \mathrm{~g}$ de soja e $25 \mathrm{~g} / 100 \mathrm{~g}$ de fécula de mandioca).

Tabela 5. Atributos sensoriais dos biscoitos.

\section{Atributos sensoriais F1}

\section{Sabor \\ Cor}

Textura

Aceitação global
$8,03 \pm 1,04^{a}$
$7,58 \pm 1,43^{a}$
$7,83 \pm 1,11^{a}$
$7,75 \pm 1,17^{a}$

\section{F2*}

$6,20 \pm 1.85^{b}$
$7,02 \pm 1,58^{a b}$
$6,42 \pm 1,78^{b}$
$6,37 \pm 1,46^{b}$

\section{F3*}

$$
\begin{aligned}
& 6,48 \pm 1,74^{b} \\
& 6,87 \pm 1,53^{b} \\
& 6,37 \pm 1,74^{b} \\
& 6,26 \pm 1,81^{b}
\end{aligned}
$$

Médias com a mesma letra, na mesma linha, não diferem entre si a $5 \%$ de probabilidade pelo teste Tukey. F1* (biscoito controle contendo farinha de trigo); F2* (biscoito contendo $30 \mathrm{~g} / 100 \mathrm{~g}$ de amaranto, $10 \mathrm{~g} / 100 \mathrm{~g}$ de quinoa, $40 \mathrm{~g} / 100 \mathrm{~g}$ de soja e $20 \mathrm{~g} / 100 \mathrm{~g}$ de fécula de mandioca); F3* (biscoito contendo $35 \mathrm{~g} / 100 \mathrm{~g}$ de amaranto, $10 \mathrm{~g} / 100 \mathrm{~g}$ de quinoa, $30 \mathrm{~g} / 100 \mathrm{~g}$ de soja e $25 \mathrm{~g} / 100 \mathrm{~g}$ de fécula de mandioca). 
Efeito da substituição da farinha de trigo no desenvolvimento de biscoitos sem glúten

VIEIRA, T. S. et al.

Apesar da amostra-controle apresentar a melhor avaliação global, notou-se que as formulações F2 e F3 apresentaram índices de aceitabilidade superiores a 70\% (Tabela 6), exceto para F2, em relação ao sabor, devido, provavelmente, ao maior teor de farinha de soja utilizada na formulação. Índices de aceitabilidade superiores a 70\% são considerados bons (MEILGAARD et al., 2007), podendo ser promissores comercialmente.

Em relação à intenção de compra (Figura 1), observou-se que, seguindo a tendência da aceitabilidade, a amostra-controle (F1) foi a que obteve maior intenção de compra (88\%), seguida das amostras F2 e F3, ambas com 53\% de intenção. Mesmo assim, evidenciou-se que mais da metade dos avaliadores comprariam as formulações 2 e 3, caso estivessem comercialmente disponíveis. É válido considerar que esse tipo de produto vem atender uma demanda específica de consumidores dispostos a investir em alternativas alimentares distintas das convencionais, com maior teor de nutrientes e alegações vinculadas à saúde. No entanto, a escolha dos ingredientes influencia diretamente a aceitação dos avaliadores, de forma que é necessário modificar e utilizar diferentes combinações para que essas características distintas influenciem minimamente a aceitação do produto.

Tabela 6. Índice de aceitabilidade dos biscoitos.

\begin{tabular}{lccc}
\multirow{2}{*}{ Atributos sensoriais } & \multicolumn{3}{c}{ Aceitabilidade (\%) } \\
\cline { 2 - 4 } & F1 $^{\text {* }}$ & F2 & F3 \\
Sabor & 98 & 67 & 80 \\
Cor & 92 & 82 & 78 \\
Textura & 97 & 73 & 75 \\
Aceitação global & 97 & 75 & 75 \\
\hline
\end{tabular}

F1* (biscoito controle contendo farinha de trigo): F2 (biscoito contendo $30 \mathrm{~g} / 100 \mathrm{~g}$ de amaranto, $10 \mathrm{~g} / 100 \mathrm{~g}$ de quinoa, $40 \mathrm{~g} / 100 \mathrm{~g}$ de soja e $20 \mathrm{~g} / 100 \mathrm{~g}$ de fécula de mandioca); F3 (biscoito contendo $35 \mathrm{~g} / 100 \mathrm{~g}$ de amaranto, $10 \mathrm{~g} / 100 \mathrm{~g}$ de quinoa, $30 \mathrm{~g} / 100 \mathrm{~g}$ de soja e $25 \mathrm{~g} / 100 \mathrm{~g}$ de fécula de mandioca).

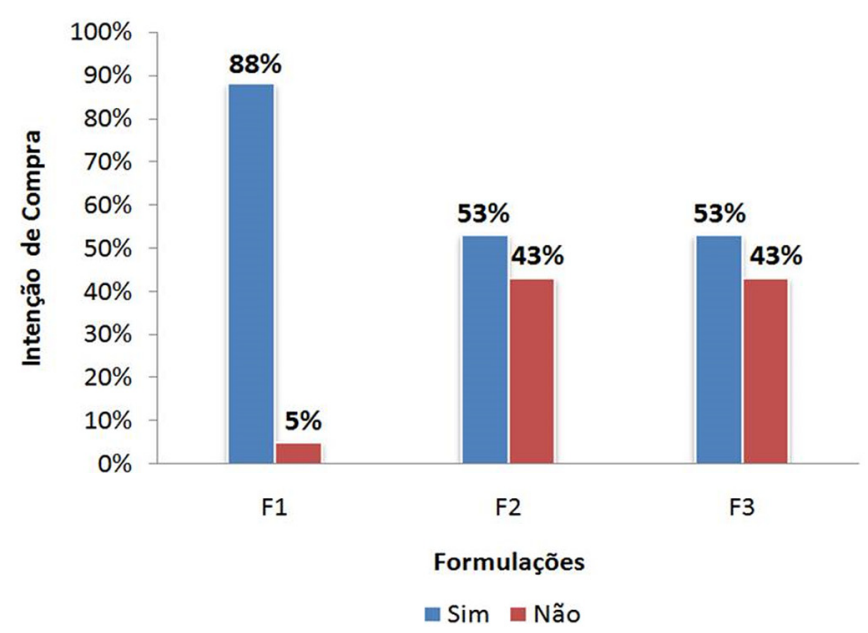

Figura 1. Intenção de compra dos avaliadores em relação aos biscoitos.
Maciel et al. (2008), ao elaborarem biscoitos tipo cracker com substituição do trigo por farinha de linhaça, observaram que aproximadamente $60 \%$ dos avaliadores responderam positivamente às amostras com $15 \mathrm{~g} / 100 \mathrm{~g}$ da farinha de linhaça, sendo que 40,62\% afirmaram que possivelmente comprariam e $25 \%$ que certamente comprariam. Esse substituto, assim como as farinhas sucedâneas utilizadas no presente estudo, pode alterar as características de textura e sabor dos biscoitos. Villarroel et al. (2009), ao elaborarem biscoitos isentos de glúten contendo farinha de avelã e de quinoa, obtiveram aceitação integral (100\%) por parte dos avaliadores portadores da doença celíaca.

\section{Conclusão}

No presente estudo, as formulações de biscoitos contendo farinhas mistas (sucedâneas ao trigo), mesmo sendo elaboradas com a ausência das proteínas do trigo responsáveis pela formação da rede de glúten, conferiram aos biscoitos características típicas e desejáveis como crocância e cor, além de terem apresentado bom rendimento. Quanto à caracterização química, as formulações contendo farinhas sucedâneas ao trigo apresentaram maior teor de resíduo mineral (cinzas), de proteínas, de lipídios e de fibras alimentares. As formulações contendo as farinhas mistas apresentaram índices de aceitabilidade superiores a $70 \%$, exceto no atributo sabor para F2, podendo ser consideradas promissoras e apontando grandes perspectivas em relação à inserção das farinhas utilizadas neste estudo em demais produtos de panificação. Destaca-se a importância dos resultados deste estudo no tocante à disponibilização de alternativas alimentares tanto para portadores de doença celíaca quanto para aqueles que almejam produtos com características nutricionais superiores aos produtos comercialmente disponíveis.

\section{Agradecimentos}

À Pró-Reitoria de Pesquisa e Pós-Graduação (PRPPG) da Universidade Federal do Espírito Santo.

\section{REFERÊNCIAS}

AGÊNCIA NACIONAL DE VIGILÂNCIA SANITÁRIA - ANVISA. Resolução n 12 , de 24 de julho de 1978. Comissão Nacional de Normas e Padrões para Alimentos (CNNPA) Agência Nacional de Vigilância Sanitário (ANVISA), Diário Oficial [da] República Federativa do Brasil, 24 jul. 1978.

AGÊNCIA NACIONAL DE VIGILÂNCIA SANITÁRIA - ANVISA. Resolução RDC n² 263, de 22 de setembro de 2005. Regulamento Técnico para Produtos de Cereais, Amidos, Farinhas e Farelos. Diário Oficial [da] República Federativa do Brasil, Brasília, DF, 23 set. 2005. 
Efeito da substituição da farinha de trigo no desenvolvimento de biscoitos sem glúten

VIEIRA, T. S. et al.

AMERICAN ASSOCIATION OF CEREAL CHEMISTS - AACC. Approved methods of the American Association of Cereal Chemists. 9. ed. Saint Paul: AACC, 1995. v. 2.

ARAÚJO, H. M. C.; ARAÚJO, W. M. C.; BOtELHO, R. B. A.; ZANDONADI, R. P. Doença celíaca, hábitos e práticas alimentares e qualidade de vida. Revista de Nutrição, Campinas, v. 23, n. 3, p. 467-474, 2010.

CAPRILES, V. D.; ARÊAS, J. A. G. Avaliação da qualidade tecnológica de snacks obtidos por extrusão de grão integral de amaranto ou de farinha de amaranto desengordurada e suas misturas com fubá de milho. Brazilian Journal of Food Technology, Campinas, v. 15, n. 1, p. 21-29, 2012. http://dx. doi. org/10.1590/S1981-67232012000100003.

CAPRILES, V. D.; ARÊAS, J. A. G. Avanços na produção de pães sem glúten: Aspectos tecnológicos e nutricionais. Boletim do Centro de Pesquisa de Processamento de Alimentos, Curitiba, v. 29, n. 1, p. 129-136, 2011

CAUVAIN S. P.; YOUNG L. Fabricación de pan. Zagoza: Acribia, 2002.

CÉSAR, A. S.; GOMES, J. C.; STALIANO, C. D.; FANNI, M. L.; BORGES, M. C. Elaboração de pão sem glúten. Revista Ceres, Viçosa, v. 53, n. 306, p. 150-155, 2006.

FERREIRA, A. M. R.; LUPARELLI, P. C. M.; SCHIEFERDECKEM, M. E. M.; VILELA, R. M. Cookies sem glúten a partir da farinha de sorgo. Archivos Latinoamericanos de Nutricion Organo: Oficial de la Sociedad Latinoamericana de Nutrición, Paraná, v. 59, n. 4, p. 433-440, 2009.

GANORKAR, P. M.; JAIN, R. K. Effect of flaxseed incorporation on physical, sensorial, textural and chemical attributes of cookies. International Food Research Journal, Selangor, v. 21, n. 4, p. 1515-1521, 2014.

GEWEHR, M. F.; DANELLI, D.; MELO, L. M.; FLÔRES, S. K.; JONG, E. V. Análises químicas em flocos de quinoa: caracterização para a utilização em produtos alimentícios. Brazilian Journal of Food Tecnology, Campinas, v. 15, n. 4, p. 280-287, 2012. http://dx.doi.org/10.1590/S1981-67232012005000023.

GIOVANELLA, C.; SCHLABITZ, C.; FERNANDA, C.; SOUZA, C. F. V. Caracterização e aceitabilidade de biscoitos preparados com farinha sem glúten. Revista Brasileira de Tecnologia Agroindustrial, Ponta Grossa, v. 7, n. 1, p. 965-976, 2013. http:// dx.doi.org/10.3895/S1981-36862013000100009.

HORWITZ, W. (Ed.). Official Methods of Analysis of the Association of Official Agriculture Chemists. Arlington: AOAC, 2005

INSTITUTO ADOLFO LUTZ. Normas analíticas do Instituto Adolfo Lutz. 4. ed. São Paulo: IAL, 2005. 1018 p.

JAY, J. M. Microbiologia de alimentos. 6. ed. Porto Alegre: Artmed, 2005.
KIRINUS, P.; COPETTI, C.; OLIVEIRA, V. R. Utilização de farinha de soja (Glycine max) e de quinoa (Chenopodium quinoa) no preparo de macarrão caseiro sem glúten. Alimentos e Nutrição, Araraquara, v. 21, n. 4, p. 555-561, 2010.

LACERDA, D. B. C. L.; SOARES, J. M. S.; BASSINELLO, P. Z.; SIQUEIRA, B. S.; KOAKUZU, S. N. Qualidade de biscoitos elaborados com farelo de arroz extrusado em substituição à farinha de trigo e fécula de mandioca. Archivos Latinoamericanos de Nutricion - Organo Oficial de la Sociedad Latinoamericana de Nutrición, Goiânia, v. 59, n. 2, p. 199-205, 2009

LEMOS, A. R.; CAPRILES, V. D.; PINTO E SILVA, M. E. M.; AREAS, J. A. G. Effect of incorporation of amaranth on the physical properties and nutritional value of cheese bread. Ciência e Tecnologia de Alimentos, Campinas, v. 32, n. 3, p. 427-431, 2012.

MACIEL, L. M. B.; PONTES, D. F.; RODRIGUES, M. C. P. Efeito da adição de farinha de linhaça no processamento de biscoito tipo cracker. Alimentos e Nutrição, Araraquara, v. 19, n. 4, p. 385-392, 2008.

MARCÍLIO, R.; AMAYA-FARFAN, J.; SILVA, M. A. A. P.; SPEHAR, C. R. Avaliação da farinha de amaranto na elaboração de biscoito sem glúten do tipo cookie. Brazilian Journal of Food Technology, Campinas, v. 8, n. 2, p. 175-181, 2005.

MARETI, M. C.; GRossmanN, M. V. E.; BENASSI, M. T. Características físicas e sensoriais de biscoitos com farinha de soja e farelo de aveia. Ciência e Tecnologia de Alimentos, Campinas, v. 30, n. 4, p. 878-883, 2010.

MARTINEZ, C. S.; RIBOTTA, P. D.; AÑÓN, M. C.; LEÓN, A. E. Effect of amaranth flour (Amaranthus mantegazzianus) on the technological and sensory quality of bread wheat pasta. Food Science \& Technology International, London, v. 20, n. 2, p. 127-135, 2014. http://dx.doi.org/10.1177/1082013213476072. PMid:23733824.

MEILGAARD, M.; CIVILLE, G. V.; CARR, B. T. Sensory evaluation techniques. 4. ed. London: CRC Press, 2007. 354 p.

MIRANDA, M.; VEGA-GÁLVEZ, A.; MARTINEZ, E.; LÓPEZ, J.; RODRÍGUEZ, M. J.; HENRÍQUEZ, K.; FUENTES, F. Genetic diversity and comparison of physicochemical and nutritional characteristics of six quinoa (Chenopodium quinoa willd.) genotypes cultivated in Chile. Ciência e Tecnologia de Alimentos, Campinas, v. 32, n. 4, p. 835-843, 2012.

MORAES, K. S.; ZAVAREZE, E. R.; MIRANDA, M. Z.; SALASMELLADO, M. M. Avaliação tecnológica de biscoitos tipo cookie com variações nos teores de lipídio e de açúcar. Ciência e Tecnologia de Alimentos, Campinas, v. 30, p. 233-242, 2010.

MOURA, F. A.; SPIER, F.; ZAVAREZE, E. R.; DIAS, A. R. G.; ELIAS, M. C. Biscoitos tipo cookie elaborados com diferentes frações de semente de abóbora (Curcubita máxima). Alimentos e Nutrição, Araraquara, v. 21, n. 4, p. 579-585, 2010. 
Efeito da substituição da farinha de trigo no desenvolvimento de biscoitos sem glúten

VIEIRA, T. S. et al.

ORDORICA-FALOMIR, C.; PAREDES-LÓPEZ, O. Effect of safflower protein isolates on cookie characteristics. International Journal of Food Science \& Technology, Oxford, v. 26, n. 1, p. 39-43, 1991. http://dx.doi.org/10.1111/j.1365-2621.1991. tb01139.x.

RAMOS, N. C.; PIEMOLINI-BARRETO, L. T.; SANDRI, I. G. Elaboração de pré-mistura para bolo sem Glúten. Alimentos e Nutrição, Araraquara, v. 23, n. 1, p. 33-38, 2012.

SCHMIELE, M.; JAEKEL, L. Z.; ISHIDA, P. M. G.; CHANG, Y. K.; STEEL, C. J. Massa alimentícia sem glúten com elevado teor protéico obtida por processo convencional. Ciência Rural, Santa Maria, v. 43, n. 5, p. 908-914, 2013. http://dx.doi. org/10.1590/S0103-84782013000500026.

UCHOA, A. M. A.; COSTA, J. M. C.; MAIA, G. A.; SILVA, M. C.; CARVALHO, A. F. F. U.; MEIRA, T. R. Parâmetros físicoquímicos, teor de fibra bruta e alimentar de pós alimentícios obtidos de resíduos de frutas tropicais. Segurança Alimentar e Nutricional, Campinas, v. 15, n. 58-65, 2008.
VIEIRA, J. C.; MONTENEGRO, F. M.; LOPES, A. S.; PENA, R. S. Qualidade física e sensorial de biscoitos doces com fécula de mandioca. Ciência Rural, Santa Maria, v. 40, n. 12, p. 2574-2579, 2010. http://dx.doi.org/10.1590/S0103-84782010001200022.

VILLARROEL, M.; HUIRIQUEO, C.; HAZBUN, J.; CARRILLO, $J$. Desarrollo de una formulación optimizada de galletas para celíacos utilizando harina desgrasada de avellana chilena (Gevuina avellana, Mol) y harina de quinoa (Chenopodium quinoa Willd). Archivos Latinoamericanos de NutricionOrgano Oficial de la Sociedad Latinoamericana de Nutrición, Temuco, v. 59, n. 2, p. 184-190, 2009.

WIESER, H. Chemistry of gluten proteins. Food Microbiology, Summit-Argo, v. 24, n. 2, p. 115-119, 2007. http://dx.doi. org/10.1016/j.fm.2006.07.004. PMid:17008153.

ZOULIAS, E. I.; OREOPOULOU, V.; KOUNALAKI, E. Effect of fat and sugar replacement on Cookie properties. Journal of the Science of Food and Agriculture, London, v. 82, n. 14, p. 1637-1644, 2002. http://dx.doi.org/10.1002/jsfa. 1230. 